\title{
Characterization of Flavonoids and Saponins from Gleditsia triacanthos by LC-ESI/MS/MS Analysis: Pharmacological Assessment of the Anti-hyperglycemic and Anti-ulcerogenic Activities of G. triacanthos methanolic Fruit Extract and its n-Butanol Fraction
}

\author{
Iman A. A. Kassem ', Sally A. El Awdan², Dalia O. Saleh",*
}

Iman A. A. Kassem', Sally A. El Awdan², Dalia O. Saleh ${ }^{2, *}$

'Chemistry of Natural Compounds Department, National Research Centre, Dokki, Cairo 12622, EGYPT.

2Pharmacology Department, National Research Centre, Dokki, Cairo 12622, EGYPT.

\section{Correspondence}

Dalia O. Saleh

Pharmacology Department, National Research Centre, Dokki, Cairo 12622. EGYPT.

E-mail: doabdelfattah@yahoo.com

History

- Submission Date: 14-01-2021;

- Review completed: 01-02-2021;

- Accepted Date: 19-02-2021.

DOI : $10.5530 / p j .2021 .13 .80$

Article Available online http://www.phcogj.com/v13/i3

Copyright

(c) 2021 Phcogj.Com. This is an openaccess article distributed under the terms of the Creative Commons Attribution 4.0 International license.

\begin{abstract}
Introduction: Gleditsia triacanthos is known to possess various pharmacological activities Objective: The composition of $n$-butanol fraction of Gleditsia triacanthos methanolic seedless fruit extract was identified from the LC-ESI/MS/MS spectra. Total methanolic extract of the seedless $G$. triacanthos fruits (MEGT) and its $n$-butanol fraction (BFGT) at three dose levels 70 , 140 and $280 \mathrm{mg} / \mathrm{kg}$ were studied for their anti-diabetic and anti-ulcerogenic effects. Materials and Methods: The anti-diabetics properties of MEGT and BFGT were orally assessed in streptozotocin (STZ; 55 mg/kg; i.p.)-induced hyperglycemic rats. Their anti-ulcerogenic activities were also evaluated in ethanol-induced peptic ulcer in rats. Results: Two phenolic acids, five flavonoids as well as four saponins were identified from BFGT. Both MEGT and BFGT showed high potential in decreasing the elevated serum glucose, total triglycerides and total cholesterol levels in rats, dose dependently, comparable with the anti-diabetic reference drug gliclazide ( $\mathrm{Glz} ; 10 \mathrm{mg} / \mathrm{kg} ;$ p.o.). They also showed an elevation insulin and $\alpha$-amylase serum levels. On the other hand, MEGT and BFGT showed significant ulceroprotective activities through decreasing both number and severity of ethanol-induced gastric lesions in rats, dose dependently, comparable with the anti-ulcer reference drug; ranitidine $(20 \mathrm{mg} / \mathrm{kg}$; p.o.) with MEGT at $280 \mathrm{mg} / \mathrm{kg}$ showing highest activity. Conclusion: From all the previous results, it can be concluded that the observed pharmacological properties are attributed to the augmented activities of the saponin and flavonoidal content of $G$. triacanthos fruits.
\end{abstract}

Key words: Anti-diabetic activity, Gleditsia triacanthos, Hypoglycemic activity, Ulceroprotective effect.

\section{INTRODUCTION}

Diabetes mellitus (DM) is a metabolic condition with chronic hyperglycemic symptoms and metabolic disorders. It is probably due to either insulin deficiency, insulin resistance or failure of $\beta$-cells of the pancreas to generate insulin, carbohydrates, fats and proteins ${ }^{1}$. Moreover, diabetic patients reportedly have a higher incidence of peptic ulcer disease. Peptic ulcer disease and DM are two serious chronic diseases with many medicals and socioeconomic consequences ${ }^{2}$. Researchers found that DM was independently associated with increased risk of peptic ulcer bleeding ${ }^{3}$. Herbal medicines with antihyperglycemic activity have been used as alternative treatments of DM due to their reduced side effects and lower cost compared to synthetic hypoglycemic drugs ${ }^{4}$. Following the World Health Organization recommendations for DM (WHO 1980), the search for safer and more effective hypoglycemic pharmaceuticals from medicinal plants has continued to be an important area of active research ${ }^{5}$.
Gleditsia triacanthos L. (Leguminosae), a $45 \mathrm{~m}$ long tree, is cultivated in Egypt public parks and gardens for ornamental purposes ${ }^{6}$. Extracts and isolates from different parts of G. triacanthos have been reported to possess different pharmacological potentials such as analgesic ${ }^{6}$, anti-oxidant ${ }^{7}$, anti-diabetic ${ }^{8}$, oncostatic and cytotoxic activities ${ }^{7,9}$

Saponins are known to be the main constituents of fruits of different Gleditsia species ${ }^{10-21}$. Also, several reports discussed the occurrence of flavonoids in different organs of Gleditsia species ${ }^{7,22-27}$

The goal of the present study was to investigate the constituents of the $n$-butanol fraction of the methanolic fruit extract of G. triacanthos (BFGT) and to assess its anti-hyperglycemic and antiulcerogenic activites in comparison to those of the total methanolic fruit extract G. triacanthos (MEGT) in male rats. To fulfill this goal, BFGT was analyzed using UPLC-ESI/MS/MS technique in the negative ion mode.

DM was induced in rats by streptozotocin (STZ); a well-known compound used to destruct the $\beta$ cells 
Kassem, et al:: Characterization of Flavonoids and Saponins from Gleditsia triacanthos by LC-ESI/MS/MS Analysis: Pharmacological Assessment of the Antihyperglycemic and Anti-ulcerogenic Activities of G. triacanthos methanolic Fruit Extract and its $n$-Butanol Fraction

of the pancreas of rats thus causing an increment in the serum glucose level as well as serum levels of triglycerides and cholesterol which were dramatically increased ${ }^{28-31}$. On the other hand, ulcers were induced in male rats by oral injection of ethyl alcohol ${ }^{32-34}$.

\section{MATERIAL AND METHODS}

\section{Plant material}

G. triacanthos fruits were obtained from The Zoological Garden, Giza, Egypt, in October 2018 and identification was confirmed by Mrs. Therese Labib senior specialist for plant identification. A voucher specimen was deposited in the Herbarium of NRC (CAIRC), Voucher Number 230.

\section{Preparation of MEGT and BFGT}

The air-dried fruits of the $G$. triacanthos $(3 \mathrm{~kg})$ were extracted with $\mathrm{CH}_{2} \mathrm{Cl}_{3}(3 \mathrm{X} 6 \mathrm{~L})$ followed by $\mathrm{MeOH}(3 \mathrm{X} 6 \mathrm{~L})$. The combined $\mathrm{MeOH}$ extract was evaporated under vacuum to yield $90 \mathrm{~g}$ of MEGT. Part of MEGT (40 g) was kept in the refrigerator until use in the pharmacological studies. The remaining part ( $50 \mathrm{~g})$ of MEGT was suspended in water and extracted with water saturated $n$-butanol $(5 \times 500 \mathrm{ml})$ to yield $43 \mathrm{~g}$ of $n$-butanol fraction (BFGT). Part of the $n$-butanol fraction $(30 \mathrm{~g})$ was kept in the refrigerator until use in the pharmacological studies. The other part (13 g) was dissolved in distilled water $(0.2 \%)$ and the aqueous solution was passed through a column packed with the polymer gel Diaion HP-20 (200 g). The adsorbed material was eluted with $\mathrm{H}_{2} \mathrm{O}, 25$, 50,75 , and $100 \%$ methanol. The 50 and $75 \%$ eluted fractions containing flavonoids were combined and freeze-dried $(7 \mathrm{~g})$. The $100 \%$ fractions containing saponins were combined and freeze dried $(5 \mathrm{~g})$. The combined flavonoidal and saponin fractions were separately subjected to LC-ESI/MS/MS analysis.

\section{UPLC-ESI/MS/MS analysis}

Ultra-performance liquid chromatographic (UPLC) analysis coupled with an ESI mass spectrometer detector allowed simultaneous isolation of the compounds and determination of the molecular weights of isolated peaks. Samples were dissolved in HPLC analytical grade methanol, filtered using a membrane disc filter $(0.2 \mu \mathrm{m})$, and subjected to UPLC-ESI-MS/MS analysis. Samples $(5 \mu \mathrm{l})$ were injected into the UPLC instrument, Waters ${ }^{\oplus}$ equipped with a reversed-phase C-18 column (ACQUITY UPLC - BEH C18 $1.7 \mu \mathrm{m}$ particle size $2.7 \mathrm{~mm}$ ). The mobile phase was filtered using a $0.2 \mu \mathrm{m}$ membrane disc filter and sonicated before injection. The Elution flow rate was adjusted to 0.2 $\mathrm{ml} / \mathrm{min}$; the gradient was composed of two eluents: water acidified with $0.1 \%$ formic acid and acetonitrile acidified with $0.1 \%$ formic acid. Negative ion modes were used on a triquadrupole (XEVO) mass spectrometry, Waters ${ }^{\otimes}$ Corporation, Milford, MA01757 U.S.A. 30 $\mathrm{eV}$ cone voltage, $3 \mathrm{kV}$ capillary voltage at $150{ }^{\circ} \mathrm{C}, 440{ }^{\circ} \mathrm{C}$ desolvation temperature were applied. Detection of mass spectra was in the ESI range $\mathrm{m} / \mathrm{z}$ 100-1000 for flavonoids and $800-1800$ for saponins using the software Maslynx 4.1 and tentatively identified by comparing the retention time (Rt) peaks in the mass spectrum and their fragmentation pattern with reported data.

\section{Laboratory animals}

Adult male Wistar albino rats (150-200 g) were used for the current experiment. Animals were obtained from the National Research Centre animal house colony. They were housed in plastic cages under standard conditions of temperature $\left(25 \pm 1^{\circ} \mathrm{C}\right)$, relative humidity $(55 \pm 10 \%)$, $12 \mathrm{~h} / 12 \mathrm{~h}$ light/dark cycles and fed on standard pellet diet and water ad libitum. The experimental protocol was approved by the Institutional Animal Ethical Committee of the National research Centre (Approval number: 13/165).

\section{Chemicals}

Streptozotocin (STZ) was obtained from Sigma-Aldrich (St. Louis, MO, USA). Gliclazide (Glz); standard drug; was obtained from Servier Canada (Laval, QC, Canada). All chemicals used were purchased from ADWIC (CAI, Egypt). All other chemicals used were of highest available analytical grade.

\section{Induction of diabetes mellitus}

Diabetes Mellitus was induced by a single i.p. injection of STZ (55 mg/ $\mathrm{kg}$ ). Rats were weighed and injected with STZ dissolved in a citrate buffer $(0.1 \mathrm{M}, \mathrm{pH} 4.5){ }^{35}$. After $48 \mathrm{~h}$ blood samples were withdrawn from the retro-orbital venous plexus under light ether anaesthesia and the serum was separated by centrifugation for the determination of glucose level. Only rats with serum glucose levels more than $200 \mathrm{mg} / \mathrm{dl}$ were selected and considered diabetic animals that have been subjected to further experimentation.

\section{Experimental design}

Diabetic rats were randomly divided into eight groups each containing 6-10 animals. Group I, the untreated diabetic group, served as the negative control group while group II served as the standard group being treated with gliclazide (Glz; $10 \mathrm{mg} / \mathrm{kg}$; p.o.) for 14 consecutive days ${ }^{36}$. Groups II, IV and V were orally treated with total methanolic extract Gleditsia triacanthos, (MGT) at the three dose levels 70, 140 and $280 \mathrm{mg} / \mathrm{kg}$, respectively. Groups VI, VII and VIII were orally given n-butanol fraction of Gleditsia triacanthos (BFGT) 70, 140 and $280 \mathrm{mg} /$ $\mathrm{kg}$; respectively. Administration of different doses of MEGT, BFGT and Glz once daily was continued for 14 days. The used doses of MEGT and BFGT were based on the acute toxicity and $\mathrm{LD}_{50}$ studies previously reported ${ }^{6}$. Moreover, a universal control group receiving only saline was observed throughout the experiment.

\section{Estimation of biochemical parameters}

At the end of the treatment, blood samples were collected from overnight fasting rats. Sera were separated for determination of serum levels of glucose, insulin, triglycerides, total cholesterol and a-amylase. The rats were then sacrificed by cervical dislocation and the liver tissues were isolated. Liver tissues were homogenized.

Serum glucose, triglycerides, and cholesterol were estimated according to the methods of Trinder $^{37}$, Fosati and prencipe ${ }^{38}$, as well as Alain et al. ${ }^{39}$, respectively. Serum insulin was estimated by a radioimmunoassay technique using the ALPCO Insulin (Rat) ELISA kit according to the method of Judzewitsch et al..$^{40}$. The activity of $a$ amylase was determined by the method of Gella et al. ${ }^{41}$. Estimation of liver reduced glutathione (GSH) was adopted according to Beutler et al. ${ }^{42}$

Gastric ulcer model induced by ethanol (Antiulcerogenic assessment)

Forty-eight male Wistar rats were randomly divided into eight groups (6 rats per group). Group I received distilled water orally and served as negative served as control while group II served as the standard control group by receiving rantidine $(20 \mathrm{mg} / \mathrm{kg}$.wt.). Groups III- V received orally 70,140 and $280 \mathrm{mg} / \mathrm{kg}$ b.wt. of MEGT, respectively. BFGT at 70,140 and $280 \mathrm{mg} / \mathrm{kg}$ b.wt. was orally administered to groups VI-VIII. Acute erosion of the gastric mucosa in fasting rats was induced by intragastric administration of absolute ethanol $(1 \mathrm{ml} \mathrm{v} / \mathrm{v})^{43}$. Animals were sacrificed after $1 \mathrm{~h}$ of ethyl alcohol administration by cervical dislocation. The stomachs were then excised along the greater curvature and examined for mucosal necrotic lesions, red streaks, and red erosions macroscopically. The total lesion number was counted and lesion severity was measured ${ }^{44}$. 
Kassem, et al:: Characterization of Flavonoids and Saponins from Gleditsia triacanthos by LC-ESI/MS/MS Analysis: Pharmacological Assessment of the Antihyperglycemic and Anti-ulcerogenic Activities of G. triacanthos methanolic Fruit Extract and its $n$-Butanol Fraction

\section{Statistical analysis}

All the results were expressed as Mean \pm S. E. Data was statistically evaluated with Graphpad prism software. Hypothesis testing methods included one-way analysis of variance (ANOVA) followed by Tukey post hoc test, whereas the ulcer number and severity were estimated using one Kruskal-Wallis non-parametric ANOVA followed by Dunn's multiple comparisons test, $\mathrm{P}<0.05$ was considered to indicate statistical significance.

\section{RESULTS}

\section{UPLC-ESI/MS/MS analysis}

The analysis of molecular masses and formulae in addition to LC-ESI/ MS/MS spectra of the $n$-butanol fraction of $G$. triacanthos methanolic fruit extract (BFGT) led to identification of 11 compounds (Table 1) including phenolic acids 1-2, flavonoids 3-7, triterpenoidal saponins (811). 4-O- and 5-O- caffeoylquinic acids ( 1 and 2 ) were identified based on the presence of a major $[\mathrm{M}-\mathrm{H}]^{-}$ion peak at $\mathrm{m} / \mathrm{z} 353$ with a fragment ion $\mathrm{m} / \mathrm{z} 191$ corresponding to a quinic acid moiety and a fragment ion at $\mathrm{m} / \mathrm{z} 179$ corresponding to a caffeic acid moiety with respect to their retention times ${ }^{45}$. This was also confirmed by the presence of a base fragment peak m/z 173 corresponding to the loss of caffeic acid and a water molecule which is a characteristic fragmentation pattern for 4-caffeoylquinic acid and can differentiate it from other isomers. The occurance of Caffeoylquinic acid in its adduct form was revealed from the presence of a fragment $[2 \mathrm{M}-\mathrm{H}]^{-}$ion peak at $\mathrm{m} / \mathrm{z} 707^{46}$.

Compounds 3 and $\mathbf{4}$ displayed principal deprotonated ion peaks at $\mathrm{m} / \mathrm{z} 287$ with typical distinctive fragmentation patterns of fustin and aromadendrin (dihydrokaempferol), respectively. Compound $\mathbf{5}$ was identified as isoquercitrin showing $[\mathrm{M}-\mathrm{H}]^{-}$ion peak at 463. It showed a typical fragmentation pattern with fragments corresponding to a deprotonated radical aglycone at m/z 300 and an aglycone at m/z 301 . Compound 7 was identified as quercetin showing $[\mathrm{M}-\mathrm{H}]^{-}$ion peak at 301 and a typical fragmentation pattern ${ }^{27}$. The detailed fragmentation pattern of compound 6 allowed the identification of luteolin-7-Oglucoside with a major base peak at $\mathrm{m} / \mathrm{z} 285$ demonstrating the loss of a hexose sugar moiety ${ }^{47}$.

The structures of the triperpenoidal saponins were established based on the $[\mathrm{M}-\mathrm{H}]^{-}$and their fragment ions corresponding to the loss of 132 (pentoses) and 162 (hexoses) mu and after considering the characteristic sugar pattern and aglycones of Gleditsia saponins ${ }^{48,49}$.

\section{Anti-hyperglycemic assessment}

\section{Effect of MEGT and BFGT on serum glucose level in diabetic rats}

Streptozotocin-induced diabetic rats exhibited significant blood glucose level increase when compared to negative control group. The standard drug Glz showed significant decrease in elevated serum glucose levels by $45 \%$ when compared to the STZ-induced diabetic group. Test groups treated with total methanol extract of MEGT at dose levels 70,140, and $280 \mathrm{mg} / \mathrm{kg}$ b.wt. showed significant decrease in elevated serum glucose levels of rats by $24 \%, 31 \%$, and $39 \%$, respectively. Similarly, treatment with $n$-butanol fraction of $G$. triacanthos (BFGT) at the same dose levels decreased elevated serum glucose levels by $34 \%$, $36 \%$ and $38 \%$, respectively in comparison to the control diabetic group (Table 2).

\section{Table 1: LC-ESI/MS-MS analysis of BFGT.}

\begin{tabular}{|c|c|c|c|c|c|}
\hline $\begin{array}{l}\text { Compound } \\
\text { number }\end{array}$ & Identified Compound & $\begin{array}{l}\text { Retention time } \\
\text { (min) }\end{array}$ & {$[\mathrm{M}-\mathrm{H}]^{-}$} & Molecular formula & MS/MS fragment ions \\
\hline & Flavonoids and Phenolics & & & & \\
\hline 1 & 5-O-Caffeoylquinic acid & 1.68 & 353 & $\mathrm{C}_{16} \mathrm{H}_{18} \mathrm{O}_{9}$ & $191,179,161,135$ \\
\hline 2 & 4-O-Caffeoylquinic acids & 1.82 & 353 & $\mathrm{C}_{16} \mathrm{H}_{18} \mathrm{O}_{9}$ & $191,179,173,135$ \\
\hline 3 & Fustin & 4.94 & 287 & $\mathrm{C}_{15} \mathrm{H}_{12} \mathrm{O}_{6}$ & $269,259,225,163,149,135,109$ \\
\hline 4 & Dihydrokaempferol (Aromadendrin) & 4.94 & 287 & $\mathrm{C}_{15} \mathrm{H}_{12} \mathrm{O}_{6}$ & $259,243,201,151,125$ \\
\hline 5 & Isoquercitrin & 5.91 & 463 & $\mathrm{C}_{21} \mathrm{H}_{20} \mathrm{O}_{12}$ & $301,300,271,255,179,175,151$ \\
\hline 6 & Luteolin 7-O-glucoside & 6.79 & 447 & $\mathrm{C}_{21} \mathrm{H}_{20} \mathrm{O}_{11}$ & $\begin{array}{c}285,240.9,266.9,256.9,242.9,216.9,199,175,151, \\
133\end{array}$ \\
\hline 7 & $\begin{array}{l}\text { Quercetin } \\
\text { Saponins }\end{array}$ & 7.63 & 301 & $\mathrm{C}_{15} \mathrm{H}_{10} \mathrm{O}_{7}$ & $179,151,121,107$ \\
\hline 8 & Caspicaoside F & 3.91 & 1777 & $\mathrm{C}_{80} \mathrm{H}_{130} \mathrm{O}_{43}$ & 1645,1615 \\
\hline 9 & Gleditsia saponin C' & 6.69 & 1615 & $\mathrm{C}_{74} \mathrm{H}_{120} \mathrm{O}_{38}$ & $1483,1349,1217,897$ \\
\hline 10 & Gleditsioside J & 6.93 & 1631 & $\mathrm{C}_{74} \mathrm{H}_{120} \mathrm{O}_{39}$ & $1499,1469,897$ \\
\hline 11 & Gleditsia saponin G' & 9.50 & 1351 & $\mathrm{C}_{64} \mathrm{H}_{104} \mathrm{O}_{30}$ & $1333,1085,965,469$ \\
\hline
\end{tabular}

\section{Table 2: Effect of MEGT and BFGT on the serum levels of glucose, triglycerides and cholesterol in STZ-treated diabetic rats}

\begin{tabular}{|c|c|c|c|}
\hline & Glucose & Triglycerides & Cholesterol \\
\hline Normal & $86.9 \pm 4.2$ & $96.4 \pm 2.5$ & $95.5 \pm 5.0$ \\
\hline STZ (55 mg/kg) & $221.8 \pm 10.6^{*}$ & $387.8 \pm 12.9^{*}$ & $153.9 \pm 12.4^{*}$ \\
\hline $\mathrm{Glz}(10 \mathrm{mg} / \mathrm{kg})$ & $120.4 \pm 11.7^{\circledR}$ & $124.1 \pm 11.3^{\circledR}$ & $89.6 \pm 6.6^{\circledR}$ \\
\hline MEGT $(70 \mathrm{mg} / \mathrm{kg})$ & $167.3 \pm 13.4^{\oplus}$ & $102.3 \pm 6.3^{\circledR}$ & $94.6 \pm 3.7^{@}$ \\
\hline MEGT $(140 \mathrm{mg} / \mathrm{kg})$ & $151.8 \pm 12.3^{\circledast}$ & $122.2 \pm 8.8^{\circledR}$ & $92.7 \pm 4.7^{\circledR}$ \\
\hline MEGT $(280 \mathrm{mg} / \mathrm{kg})$ & $134.15 \pm 8.4^{\oplus}$ & $148.2 \pm 7.9^{\circledR}$ & $87.5 \pm 7.6^{\circledR}$ \\
\hline BFGT $(70 \mathrm{mg} / \mathrm{kg})$ & $144.6 \pm 6.8^{\circledR}$ & $151.9 \pm 11.7^{\circledR}$ & $79.9 \pm 6.2^{@}$ \\
\hline BFGT $(140 \mathrm{mg} / \mathrm{kg})$ & $141.4 \pm 3.8^{\circledR}$ & $153.5 \pm 13.8^{\circledR}$ & $78.2 \pm 6.7^{@}$ \\
\hline BFGT $(280 \mathrm{mg} / \mathrm{kg})$ & $137.2 \pm 5.6 @$ & $148.8 \pm 11.8 @$ & $73.88 \pm 6.8 @$ \\
\hline
\end{tabular}

Results are expressed as means \pm SEM. Statistical analysis was carried out by ANOVA followed by Tukey's multiple comparisons test. ${ }^{*}$ Significant difference from normal group at $\mathrm{P}<0.05$. @ Significant difference from STZ-treated group at $\mathrm{P}<0.05$. 
Kassem, et al:: Characterization of Flavonoids and Saponins from Gleditsia triacanthos by LC-ESI/MS/MS Analysis: Pharmacological Assessment of the Antihyperglycemic and Anti-ulcerogenic Activities of G. triacanthos methanolic Fruit Extract and its $n$-Butanol Fraction

\section{Effect of MEGT and BFGT on serum insulin level in diabetic rats}

Test group receiving STZ showed a $54 \%$ decrease in serum insulin level. Glz produced a significant increase of $131 \%$ in reduced serum insulin in comparison to the STZ-induced diabetic rats. Rats treated with MEGT at 70, 140 and $280 \mathrm{mg} / \mathrm{kg}$ significanly increased the levels of reduced serum insulin by $63 \%, 126 \%$ and $146 \%$, respectively while rats treated with BFGT at 70, 140, $280 \mathrm{mg} / \mathrm{kg}$ b.wt. exhibited an increase of $122 \%, 108 \%$ and $168 \%$ when compared to the control group (Figure 1a).

\section{Effect of MEGT and BFGT on serum a-amylase activity in diabetic rats}

Diabetic rats exhibited a $68 \%$ significant decrease in the activity of serum $\alpha$-amylase activity when compared to normal control group. Group treated with standard drug Glz showed a $156 \%$ significant increase in the serum $\alpha$-amylase activity when compared to group of diabetic rats. MEGT and BFGT at 70, 140 and $280 \mathrm{mg} / \mathrm{kg}$ b.wt. dose levels showed significant increase of $172 \%, 167 \%, 152 \%$ and $130 \%, 125 \%, 112 \%$, respectively in the serum amylase activity, in comparison to the control diabetic group (Figure 1b).

\section{Effect of MEGT and BFGT on serum levels of MDA and GSH in diabetic rats}

A significant 2.9-fold increment of serum MDA was shown in the diabetic rats in comparison with the normal control group. Glz exhibited significant decrease in the serum MDA of STZ-induced diabetic rats by $56 \%$ as compared to the diabetic control group. Treatment with MEGT $(70,140$ and $280 \mathrm{mg} / \mathrm{kg}$ ) exerted significant decrease in the serum MDA by $43 \%, 57 \%$ and $59 \%$, respectively, while treatment with SFGT $(70,140$ and $280 \mathrm{mg} / \mathrm{kg}$ ) showed significant decrease in the serum MDA level by $24 \%, 32 \%$ and $40 \%$ respectively as compared to the control diabetic group.

Moreover, STZ-induced diabetic rats showed $71 \%$ decrease in serum GSH in comparison to normal control group. Group of diabetic rats treated with Glz showed significant increase in the serum GSH level 175 (a)

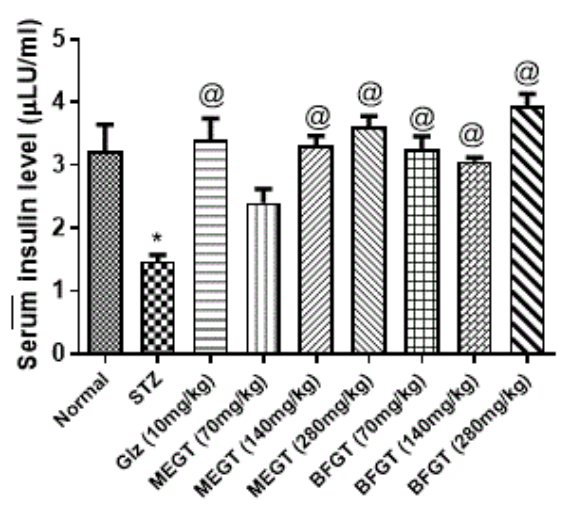

(b)

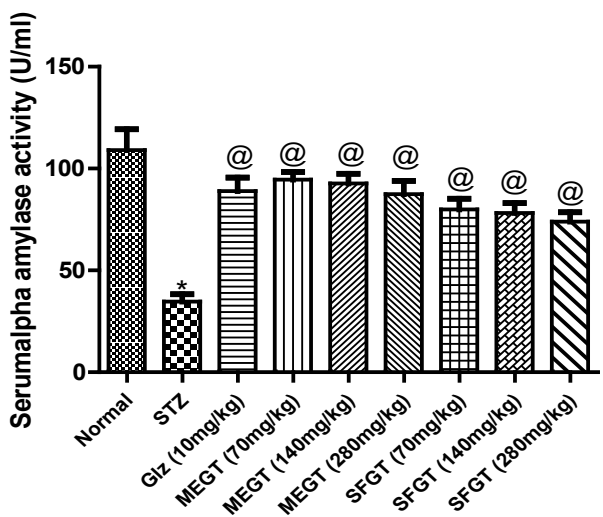

Figure 1: Effect of MEGT and BFGT on the serum levels of insulin (a) and amylase (b) in STZ-treated diabetic rats. Results are expressed as means \pm SEM. Statistical analysis was carried out by ANOVA followed by Tukey's multiple comparisons test. ${ }^{*}$ Significant difference from normal group at $P<0.05$. ${ }^{\circledR}$ Significant difference from STZ-treated group at $P<0.05$.

(a)

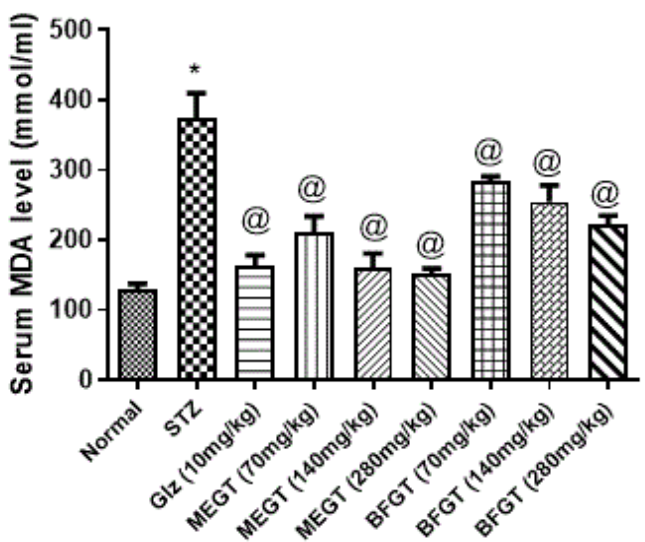

(b)

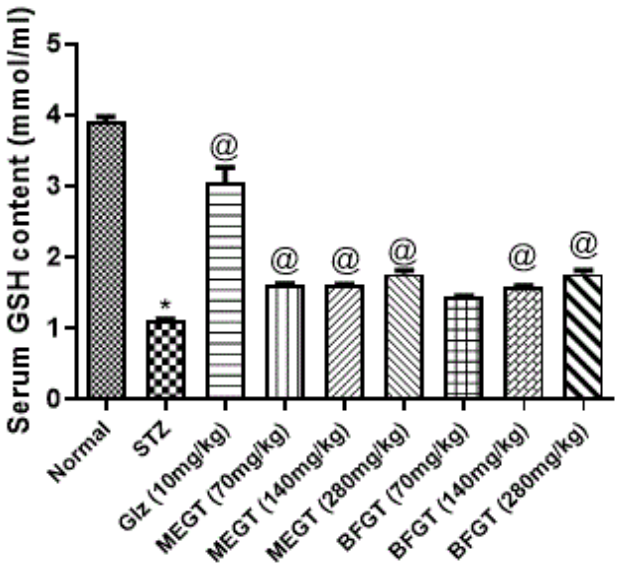

Figure 2: Effect of MEGT and SFGT on the serum levels of lipid peroxides (a), reduced GSH (b) in STZ-treated diabetic rats. Results are expressed as means \pm SEM. Statistical analysis was carried out by ANOVA followed by Tukey's multiple comparisons test. * Significant difference from normal group at $P<0.05$. ${ }^{\circledR}$ Significant difference from STZ-treated group at $\mathrm{P}<0.05$. 
Kassem, et al:: Characterization of Flavonoids and Saponins from Gleditsia triacanthos by LC-ESI/MS/MS Analysis: Pharmacological Assessment of the Antihyperglycemic and Anti-ulcerogenic Activities of G. triacanthos methanolic Fruit Extract and its $n$-Butanol Fraction

$\%$ when compared to the control diabetic group. Treatment with MEGT $(70,140$ and $280 \mathrm{mg} / \mathrm{kg})$ showed significant increase in the serum GSH level by $45 \%, 45 \%$ and $59 \%$, respectively, whereas treatment with BFGT $(70,140$ and $280 \mathrm{mg} / \mathrm{kg}$ ) exerted a serum GSH level increment by $30 \%$, $42 \%$ and $59 \%$, respectively as compared to the control diabetic group (Figure 2a,b).

\section{Effect of MEGT and BFGT on serum levels of triglycerides and total cholesterol in diabetic rats}

A significant increase of elevated serum triglycerides and total cholesterol levels reaching 5 folds and 1.6 folds, respectively was shown in STZ-induced diabetic rats in comparison to normal control ones. Group treated with $\mathrm{Glz}$ produced significant decrease in elevated serum triglycerides and total cholesterol levels by $68 \%$ and $41 \%$ when compared to the STZ-induced diabetic group. Groups treated with MGT and SGT at 70, 140 and $280 \mathrm{mg} / \mathrm{kg}$ b.wt. showed significant decrease in elevated serum triglyceride level by $73 \%, 68 \%, 61 \%$ and 60 $\%, 60 \%, 61 \%$, respectively in comparison to the control diabetic group (Table 2).

Similarly, test groups treated with MGT and SGT at 70,140 and 280 $\mathrm{mg} / \mathrm{kg}$ b.wt. exhibited significant decrease in elevated serum total cholesterol level by $38 \%, 39 \%, 42 \%$, and $47 \%, 49 \%, 51 \%$, respectively, in comparison to the diabetic group.

\section{Anti-ulcerogenic assessment}

\section{Effect of MEGF and BFGF on serum ulcer number and severity in ethanol-induced ulcer rat model}

MEGT and BFGT showed significant ulceroprotective activity where they showed a significant decrease in both number and severity of ethanol induced gastric lesions in rats when compared to control group. receiving standard drug ranitidine (20 $\mathrm{mg} / \mathrm{kg}$ b.wt.). MEGT at its highest dose level ( $280 \mathrm{mg} / \mathrm{kg}$ b.wt.) showed inhibition of ulcer number and severity by 70 and $82 \%$, respectively.

BFGT at 140 and $280 \mathrm{mg} / \mathrm{kg}$ b.wt. decreased the number and severity of gastric lesions in rats by $80 \%, 83 \%$ and $85 \%, 96 \%$, respectively when compared to the control group. Group IV receiving SGT at $70 \mathrm{mg} / \mathrm{kg}$ b.wt. showed only a significant inhibition in ulcer number with a $73 \%$ protection. These effects were comparable with standard reference drug ranitidine $(20 \mathrm{mg} / \mathrm{kg})$ (Table 3$)$.

\section{DISCUSSION}

The composition of BFGT was identified from the LC-ESI/MS/MS spectra. One phenolic acid and its dimer, five flavonoids and four saponins were characterized. The five identified flavonoids were previously reported from various parts of different Gleditsia species. Fustin and dihydrokaempferol were previously detected in the spines of $G$. sinensis ${ }^{26,27}$, Isoquercitrin previously detected from spines of $G$. sinensis was isolated from the leaves of G. sinensis ${ }^{23}$, G. japonica ${ }^{22}$ and $G$. triacanthos ${ }^{7,24}$. Luteolin-7-O-glucoside was previously isolated from leaves of G. japonica ${ }^{22}$, G. triacanthos ${ }^{7}$ and G. sinensis ${ }^{23}$. Quercetin was previously reported from spines of $G$. sinensis ${ }^{26}$, G. japonica leaves ${ }^{22}$ and $G$. triacanthos leaves ${ }^{24}$. The two Caffeoylquinic acid isomers were previously isolated from leaves of $G$. japonica ${ }^{22}$ whereas 5-O-caffeoylquinic acid was detected in $G$. triacanthos leaves ${ }^{50}$.

The saponin structures were established based on their MS data ${ }^{48}$ and guided by their characteristic sugar pattern ${ }^{10-20,51}$. The identified saponins reported here for the first time were caspicaoside $\mathrm{F}$ previously isolated from G. caspica fruits ${ }^{10}$, Gleditsia saponin C' was previously isolated from $G$. sinensis ${ }^{12,20,21}$ and also obtained after partial alkaline hydrolysis of Gleditsia saponin C from G. japonica ${ }^{52}$, Gledtsioside J was isolated before from fruits of G. sinensis ${ }^{20}$ and gleditsia saponin G' was previously obtained from G. japonica after alkaline hydrolysis of Gleditsia saponin $\mathrm{G}^{51}$.

The impact of MEGT and BFGT on the STZ-induced hyperglycemia and their role in lowering the serum lipids in diabetic rats was also investigated in the current study. The results showed that MEGT and BFGT at the three dose levels $(70,140$ and $280 \mathrm{mg} / \mathrm{kg}$ b.wt.) markedly decreased the elevated serum glucose levels of diabetic rats' dose dependently in comparison to the control diabetic group. On the other hand, oral treatment of diabetic rats with MEGT and BFGT also dramatically elevated the serum levels of insulin and $\alpha$-amylase in a dose dependent manner. It has been previously proven that DM is closely associated to hyperlipidemia. Lack of insulin secretion in diabetic patients develops hydrolysis of triglycerides into diglycerides, unesterified fatty acids and free glycerol ${ }^{53}$. The fatty acids may be reesterified into triglycerides may leading to hypertriglyceridemia that activates the mechanism by which DM causes hyperlipidemia ${ }^{54}$. The current study showed that treatment with MEGT and BFGT exhibited significant decrease in elevated serum levels of triglycerides and total cholesterol in comparison to the control diabetic group.

Oxidative stress is the hallmark of the pathogenesis of DM. On the other hand, the ability of anti-oxidants to protect against the deleterious effects of hyperglycemia and also to enhance glucose metabolism and uptake, should be considered as a lead alternative in DM treatment. In the present study, STZ-induced diabetes was associated with a marked elevation in the oxidative stress biomarkers evidenced by significant elevation of serum MDA as well as decrease in serum GSH in comparison to normal control group. Oral treatment with MEGT and BFGT exerted prominent decline in the serum MDA and exerted a serum GSH level increment as compared to the control diabetic group.

Furthermore,DM has been previously reported to increase vulnerability of the gastric mucosa to various ulcerogens. The remarkable alterations observed in patients with chronic DM decrease gastric secretion and motility ${ }^{55}$. In the current research the impact of MEGT and BFGT on ethanol induced ethanol-induced ulcer in rats at three dose levels 70 ,

Table 3: Effect of MEGT and BFGT on ethanol-induced ulcer number and severity.

\begin{tabular}{ccccc}
\hline & Ulcer number & \%Protection & Ulcer severity & \%Protection \\
\hline Saline & $12.64 \pm 0.741$ & & $43.09 \pm 3.212$ & \\
Ranitidine $(20 \mathrm{mg} / \mathrm{kg})$ & $0.5 \pm 0.25^{*}$ & 96.04 & $0.72 \pm 0.83^{*}$ & $16 \pm 1.929$ \\
MEGT $(70 \mathrm{mg} / \mathrm{kg})$ & $4.83 \pm 0.792$ & 61.78797468 & $11.16 \pm 1.706$ & 62.86841495 \\
MEGT $(140 \mathrm{mg} / \mathrm{kg})$ & $4.33 \pm 0.802$ & 65.74367089 & $7.5 \pm 0.807^{*}$ & 74.10071942 \\
MEGT $(280 \mathrm{mg} / \mathrm{kg})$ & $3.67 \pm 0.210^{*}$ & 70.96518987 & $14.16 \pm 0.435$ & 82.59456951 \\
BFGT (70mg/kg) & $3.33 \pm 0.333^{*}$ & 73.65506329 & $7 \pm 0.849^{*}$ & 67.13854723 \\
BFGT (140mg/kg) & $2.50 \pm 0.428^{*}$ & 80.22151899 & $1.66 \pm 0.732^{*}$ & 83.75493154 \\
BFGT $(280 \mathrm{mg} / \mathrm{kg})$ & $1.83 \pm 0.703^{*}$ & 85.5221519 & 96.14759805 \\
\hline
\end{tabular}

Results were expressed as mean \pm SEM. Statistical analysis was carried out by one Kruskal-Wallis non-parametric ANOVA followed by Dunn's multiple comparisons test. ${ }^{*}$ Significant difference from saline control group $\mathrm{P}<0.05$ 
Kassem, et al:: Characterization of Flavonoids and Saponins from Gleditsia triacanthos by LC-ESI/MS/MS Analysis: Pharmacological Assessment of the Antihyperglycemic and Anti-ulcerogenic Activities of G. triacanthos methanolic Fruit Extract and its $n$-Butanol Fraction

140 and $280 \mathrm{mg} / \mathrm{kg}$ b.wt., was also assessed. MEGT and BFGT showed a substantial decrease in the amount and intensity of ethanol-induced gastric lesions in rats, relative to the rats receiving the standard drug ranitidine $(20 \mathrm{mg} / \mathrm{kg}$ b.wt.), indicating prominent ulceroprotective efficacy. At its highest dose level, MEGT ( $280 \mathrm{mg} / \mathrm{kg}$ b.wt.) demonstrated significant inhibition of the number and severity of ulcers. Moreover, flavonoid and saponin rich BFGT decreased the number and severity of gastric lesions in rats when compared to the ranitidine treated group in a dose dependent manner.

The anti-diabetic and anti-ulcerogenic effect of MEGT and BFGT might be attributed to its high content of flavonoids and saponins where both classes were reported to possess both activities. Flavonoids were reported to show anti-diabetic and anti-oxidant activities ${ }^{56-58}$. Flavonoids described in the current study were previously reported to possess anti-hyperglycemic activity. Isoquercitrin showed protective activity against DM ${ }^{59}$ and improved insulin sensitivity ${ }^{60}$ and quercetin caused significant decrease in blood glucose level and attenuated oxidative stress associated with diabetes in rats ${ }^{61,62}$. Moreover, luteolin7-O-glucoside was reported to ameliorated $\mathrm{DM}^{63}$ and inhibited alpha amylase activity ${ }^{64}$. Also, caffeoylquinic acid-rich extract from Pandanus tectorius fruit decreased insulin resistance and modulates hepatic glucose and lipid metabolism in diabetic mice ${ }^{65}$.

Flavonoids were also reported in literature to exhibit anti-ulcerogenic activities by protecting the gastrointestinal mucosa from lesions through the contribution of various mechanisms ${ }^{66}$. Flavonoidal fractions from different plants were reported to possess anti-ulcer activities ${ }^{67}$. Moreover, flavonoidal fraction from $G$. triacanthos leaves exhibited anti-oxidant activity with luteolin 7-O-glucoside showing highest free radical scavenging activity ${ }^{7}$. Luteolin $7-O$ - glucoside also was reported to provide protective effects in the rat gastric mucosa against ethanolinduced gastric injury ${ }^{68}$. Quercetin possesses beneficial effects on ulcer formation and gastric secretions in rat experimental ulcer model. However, the anti-ulcer activity of quercetin is attributed to its antioxidant property, which involves free radical scavenging and reduction of lipid peroxidation ${ }^{69}$. Moreover, caffeoylquinic acid-rich extract from Ligularia stenocephala ${ }^{70}$ and isolated dicaffeoylquinic acid isomer from Arctium lappa ${ }^{71}$ exhibited significant anti-ulcer effect.

The anti-diabetic activities of MEGT and SFGT might also be attributed to its triterpenoidal saponin component. Triterpenoidal saponin rich fraction from Stauntonia chinensis was reported to exhibit hypoglycemic and hypolipidemic effects in $\mathrm{db} / \mathrm{db}$ mice ${ }^{72}$. Similarly, Singh et al. (2014) has reported the anti-diabetic potential of triterpenoid saponin isolated from Primula denticulate where it declined blood glucose via elevating insulin secretion from pancreatic $\beta$-cells ${ }^{73}$. Furthermore, the hypoglycemic property of triterpenoid saponin isolated from Polyscias fruticosa leaves ${ }^{74}$ inhibited porcine pancreas $\alpha$-amylase and prominently reduced the postprandial blood glucose level in a highsucrose diet fed mice.

Previous reports also showed potent protective effect of the saponin fractions from different origins on ethanol- and indomethacin-induced gastric mucosal lesions in rats. The saponin fraction from the Camellia sinensis (tea plant) seeds and its triterpenoidal saponin isolates were previously reported to possess a marked ulceroprotective activity against ethanol-induced gastric lesions ${ }^{75}$. Conyza blinii extract rich with triterpenoidal saponins was reported to exhibit an intense protection activity against ethanol-induced gastric ulcers through scavenging of free radicals, suppressing the inflammatory responses thus protecting the gastric mucosa ${ }^{76}$.

\section{CONCLUSION}

The present study showed prominent evidence on the anti-diabetic and anti-ulcerogenic activities of MEGT and BFGT evaluated by STZ-induced diabetes and ethanol-induced gastric ulcers in rats, respectively. The anti-diabetic and the anti-ulcerogenic properties of MEGT and BFGT may be attributed to the combined activities of their saponins and flavonoidal constituents.

\section{CONFLICTS OF INTEREST}

None.

\section{REFERENCES}

1. American Diabetes, A., Diagnosis and classification of diabetes mellitus. Diabetes care, 2009. 32 Suppl 1(Suppl 1): p. S62-S67.

2. Tacheci, I. and J. Bures, [Peptic ulcer disease in patients with diabetes mellitus]. Vnitr Lek, 2011. 57(4): p. 347-350

3. Peng, Y.L., et al., Diabetes is an independent risk factor for peptic ulcer bleeding: a nationwide population-based cohort study. J Gastroenterol Hepatol, 2013. 28(8): p. 1295-1299.

4. Choudhury, H., et al., An update on natural compounds in the remedy of diabetes mellitus: A systematic review. Journal of traditional and complementary medicine, 2017. 8(3): p. 361-376.

5. Jung, M., et al., Anti-diabetic agents from medicinal plants. Curr Med Chem, 2006. 13(10): p. 1203-1218.

6. Saleh, D.O., I. Kassem, and F.R. Melek, Analgesic activity of Gleditsia triacanthos methanolic fruit extract and its saponin-containing fraction. Pharmaceutical Biology, 2016. 54(4): p. 576-580.

7. Mohammed, R., et al., Flavonoid constituents, cytotoxic and antioxidant activities of Gleditsia Triacanthos L. Leaves. Saudi Journal of Biological Sciences, 21(6): p. 547-553.

8. Mohammed, R., et al., Anti-diabetic and cytotoxic activities of Gleditsia triacanthos L. leaves. Planta Medica, 2013. 79(13): p. 175.

9. Sokoloff, B., et al., The oncostatic factors present in gleditschia triacanthos. A critical study. Growth, 1964. 28: p. 97-103.

10. Melek, F.R., et al., Caspicaosides E-K, triterpenoid saponins and cytotoxic acylated saponins from fruits of Gleditsia caspica Desf. Phytochemistry, 2014. 100: p. 110-119.

11. Miyase, T., et al., Cytotoxic triterpenoid saponins acylated with monoterpenic acids from fruits of Gleditsia caspica Desf. Phytochemistry, 2010. 71(16): p. 1908-1916.

12. Teng, R., et al., A new triterpenoid saponin GS-C^ from Gleditsia delavayi. Acta Botanica Yunnanica, 2002. 24(4): p. 531-534.

13. Teng, R.W., et al., Two new complex triterpenoid saponins from Gledistsia dolavayi Franch. Magnetic Resonance in Chemistry, 2002. 40(9): p. 609-613.

14. Zhang, Z., et al., Four new triterpenoidal saponins acylated with one monoterpenic acid from Gleditsia sinensis. J Nat Prod, 1999. 62(5) p. 740-745.

15. Zhang, Z., et al., Gleditsiosides N-O, New Triterpenoid Saponins from Gleditsia sinensis. Journal of Natural Products, 1999. 62(6): p. 877-881.

16. Zhang, Z., et al., Triterpenoidal saponins acylated with two monoterpenic acids from Gleditsia sinensis. Chemical \&amp pharmaceutical bulletin, 1999. 47(3): p. 388-393.

17. Konoshima T. and T. Sawada. Legume Saponins of Gleditsia japonica MIQUEL. V. 13C Nuclear Magnetic Resonance Spectral Studies on the Structures of Gleditsia Saponins D2, G and I. Chemical \& Pharmaceutical Bulletin 1982. 30(11): 4082-4087.

18. Melek, F.R., et al., Three further triterpenoid saponins from Gleditsia caspica fruits and protective effect of the total saponin fraction on cyclophosphamide-induced genotoxicity in mice. Zeitschrift für Naturforschung C, 2015. 70(1-2): p. 31-37.

19. Kassem, I.A.A., et al., Two new acylated triterpenoidal saponins from Gleditsia caspica Desf. and the effect of its saponin content on LPS induced cognitive impairment in mice. Phytochemistry Letters, 2020 40: p. 53-62.

20. Zhang, Z., et al., Triterpenoidal saponins from Gleditsia sinensis Phytochemistry, 1999. 52(4): p. 715-722.

21. Miyase, T., et al., Bisdesmosidic Saponins From Fruits OF Gleditsia Caspica Desf. Rev. Latinoamer. Quím. , 2009. 37(3): p. 218-229.

22. Hwang, Y.J., et al., Chemical study on the phenolic compounds from Gleditsia japonica. 1994. 25: p. 11-19.

23. Yoshizaki, M., T. Tomimori, and T. Namba, Pharmacognostical studies on Gleditsia. III. Flavonoidal constituents in the leaves of Gleditsia japonica Miquel and G. sinensis Lamarck. Chemical \& Pharmaceutical Bulletin, 1977. 25: p. 3408-3409. 
Kassem, et al:: Characterization of Flavonoids and Saponins from Gleditsia triacanthos by LC-ESI/MS/MS Analysis: Pharmacological Assessment of the Antihyperglycemic and Anti-ulcerogenic Activities of G. triacanthos methanolic Fruit Extract and its $n$-Butanol Fraction

24. Duchenko, M., O. Demeshko, and V. Kovalev, Flavonoids from Gleditsia triacanthos. Chemistry of Natural Compounds, 2016. 52.

25. Panova, D.I. and E.S. Georgieva, Study of the flavonoid composition of Gleditschia triacanthos leaves. Dokl Bolg Lkad. Nauk., 1972. 25: p. 71-74.

26. Zhou, L., et al., Antibacterial phenolic compounds from the spines of Gleditsia sinensis Lam. Natural Product Research, 2007. 21: p. 283291.

27. Li, J., et al., HPLC-MS/MS determination of flavonoids in Gleditsiae Spina for its quality assessment. Journal of Separation Science, 2018. 41(8): p. 1752-1763.

28. King, A.J.F., The use of animal models in diabetes research. British journal of pharmacology, 2012. 166(3): p. 877-894.

29. Saleh, D.O., et al., Streptozotocin-induced vascular and biochemical changes in rats: Effects of rosiglitazone vs. metformin. Bulletin of Faculty of Pharmacy, Cairo University, 2013. 51(2): p. 131-138.

30. Damasceno, D.C., et al., Streptozotocin-induced diabetes models: pathophysiological mechanisms and fetal outcomes. BioMed research international, 2014. 2014: p. 819065-819065.

31. El-Awdan, S.A., G.A. Abdel Jaleel, and D.O. Saleh, Grape seed extract attenuates hyperglycaemia-induced in rats by streptozotocin. Bulletin of Faculty of Pharmacy, Cairo University, 2013. 51(2): p. 203-209.

32. Arab, H.H., et al., Diosmin protects against ethanol-induced gastric injury in rats: novel anti-ulcer actions. PloS one, 2015. 10(3): p. e0122417-e0122417.

33. Guzmán-Gómez, O., et al., Amelioration of Ethanol-Induced Gastric Ulcers in Rats Pretreated with Phycobiliproteins of Arthrospira (Spirulina) Maxima. Nutrients, 2018. 10(6): p. 763.

34. El-Hawary, S.S., et al., Metabolomic profiling of five Agave leaf taxa via UHPLC/PDA/ESI-MS inrelation to their anti-inflammatory, immunomodulatory and ulceroprotective activities. Steroids, 2020. 160: p. 108648.

35. Brosky, G. and J. Logothetopoulos, Streptozotocin diabetes in the mouse and guinea pig. Diabetes, 1969. 18(9): p. 606-611.

36. Nicholas, W., Insulin in General Practice. N S Med Bull, 1965. 44: p 147-148.

37. Trinder, P., Determination of blood glucose using 4-amino phenazone as oxygen acceptor. J Clin Pathol, 1969. 22(2): p. 246.

38. Fossati, P. and L. Prencipe, Serum triglycerides determined colorimetrically with an enzyme that produces hydrogen peroxide. Clin Chem, 1982. 28(10): p. 2077-2080.

39. Allain, C.C., et al., Enzymatic determination of total serum cholesterol. Clin Chem, 1974. 20(4): p. 470-475.

40. Judzewitsch, R.G., et al., Chronic chlorpropamide therapy of noninsulin-dependent diabetes augments basal and stimulated insulin secretion by increasing islet sensitivity to glucose. J Clin Endocrinol Metab, 1982. 55(2): p. 321-328.

41. Gella, F.J., et al., Determination of total and pancreatic alpha-amylase in human serum with 2-chloro-4-nitrophenyl-alpha-D-maltotrioside as substrate. Clin Chim Acta, 1997. 259(1-2): p. 147-160.

42. Beutler, E., O. Duron, and B.M. Kelly, Improved method for the determination of blood glutathione. J Lab Clin Med, 1963. 61: p. 882888.

43. A. Robert, J.E. Nezamis, C. Lancaster, A.J. Hanchar, Cytoprotection by prostaglandins in rats. Prevention of gastric necrosis produced by alcohol, $\mathrm{HCl}, \mathrm{NaOH}$, hypertonic $\mathrm{NaCl}$, and thermal injury, Gastroenterology 77 (1979) 433-443.

44. G. Mozsik, F. Moron, T. Javor, Cellular mechanisms of the development of gastric mucosal damage and of gastrocytoprotection induced by prostacyclin in rats, A pharmacological study. Prostaglandins Leukot Med 9 (1982) 71-84

45. Willems, J.L., et al., Analysis of a series of chlorogenic acid isomers using differential ion mobility and tandem mass spectrometry. Analytica Chimica Acta, 2016. 933: p. 164-174.

46. Chandradevan, M., et al., UHPLC-ESI-Orbitrap-MS Analysis of Biologically Active Extracts from Gynura procumbens (Lour.) Merr. and Cleome gynandra L. Leaves. Evidence-Based Complementary and Alternative Medicine, 2020: p. 3238561.

47. Li, Z.-H., et al., Rapid Identification of Flavonoid Constituents Directly from PTP1B Inhibitive Extract of Raspberry (Rubus idaeus L.) Leaves by HPLC-ESI-QTOF-MS-MS. Journal of chromatographic science, 2016. 54(5): p. 805-810.

48. Wang, S., et al., Separation and Characterization of Triterpenoid Saponins in Gleditsia sinensis by Comprehensive Two-Dimensional Liquid Chromatography Coupled with Mass Spectrometry. Planta Medica, 2016. 82.

49. Kılınç, H., et al., Phytochemical investigation of Scabiosa sicula guided by a preliminary HPLC-ESIMSn profiling. Phytochemistry, 2020. 174: p. 112350.

50. Bozhilov, D., et al., Chemical composition of gleditsia triacanthos I. -Application in phytotherapy of socially significant diseases. Materials, Methods \& Technologies, 2014. 8: 382-392.

51. Konoshima, T., Y. Umegaki, and T. Sawada, Legume Saponins of Gleditsia japonica MIQUEL. III. Further desmonoterpenyl glycosides of echinocystic acid. Chemical \& pharmaceutical bulletin, 1981. 29(9): p. 2695-2699.

52. Konoshima, T., et al., Legume saponin of Gleditisia japonica Miquel Il desmonoterpenyl glycoside of echinocystic acid. Chemical \& pharmaceutical bulletin, 1980. 28(12): p. 3473-3478.

53. Ebara, T., et al., Hyperlipidemia in streptozocin-diabetic hamsters as a model for human insulin-deficient diabetes: comparison to streptozocin-diabetic rats. Metabolism, 1994. 43(3): p. 299-305.

54. Saudek, C.D. and H.A. Eder, Lipid metabolism in diabetes mellitus. Am J Med, 1979. 66(5): p. 843-852

55. Owu, D.U., et al., Gastric Ulceration in Diabetes Mellitus: Protective Role of Vitamin C. ISRN Gastroenterology, 2012. 2012: p. 362805.

56. Fawzy, G.A., et al., Anti-diabetic and anti-oxidant activities of major flavonoids of Cynanchum acutum L. (Asclepiadaceae) growing in Egypt. Z Naturforsch C J Biosci, 2008. 63(9-10): p. 658-662.

57. Sarian, M.N., et al., Anti-oxidant and Anti-diabetic Effects of Flavonoids: A Structure-Activity Relationship Based Study. BioMed research international, 2017. 2017: p. 8386065-8386065.

58. Al-Ishaq, R.K., et al., Flavonoids and Their Anti-Diabetic Effects: Cellular Mechanisms and Effects to Improve Blood Sugar Levels. Biomolecules, 2019. 9(9). p. 430.

59. Valentová, K., et al., Isoquercitrin: Pharmacology, toxicology, and metabolism. Food and Chemical Toxicology, 2014. 68: p. 267-282.

60. Zhang, L., et al., Hypoglycemic effect and mechanism of isoquercitrin as an inhibitor of dipeptidyl peptidase- 4 in type 2 diabetic mice. RSC Advances, 2018. 8: p. 14967-14974.

61. Roslan, J., et al., Quercetin ameliorates oxidative stress, inflammation and apoptosis in the heart of streptozotocin-nicotinamide-induced adult male diabetic rats. Biomedicine \& Pharmacotherapy, 2017. 86 p. 570-582

62. Sanders, R., F. Rauscher, and J. Watkins, Effect of Quercetin on antioxidant defence in streptozotocin-induced diabetic rats. Journal of biochemical and molecular toxicology, 2001. 15: p. 143-149.

63. Zang, Y., K. Igarashi, and Y. Li, Anti-diabetic effects of luteolin and luteolin-7-O-glucoside on KK-Ay mice. Bioscience, Biotechnology, and Biochemistry, 2016. 80(8): p. 1580-1586.

64. Kim, J.-S., C.-S. Kwon, and K.H. Son, Inhibition of Alpha-glucosidase and Amylase by Luteolin, a Flavonoid. Bioscience, Biotechnology, and Biochemistry, 2000. 64(11): p. 2458-2461.

65. Wu, C., et al., The caffeoylquinic acid-rich Pandanus tectorius fruit extract increases insulin sensitivity and regulates hepatic glucose and lipid metabolism in diabetic db/db mice. J Nutr Biochem, 2014 25(4): p. 412-419.

66. Mota, K.S., et al., Flavonoids with gastroprotective activity. Molecules, 2009. 14(3): p. 979-1012

67. Coelho, R.G., et al., Gastric anti-ulcer activity of leaf fractions obtained of polar extract from Wilbrandia ebracteata in mice. Nat Prod Res, 
Kassem, et al:: Characterization of Flavonoids and Saponins from Gleditsia triacanthos by LC-ESI/MS/MS Analysis: Pharmacological Assessment of the Antihyperglycemic and Anti-ulcerogenic Activities of G. triacanthos methanolic Fruit Extract and its n-Butanol Fraction

\section{23(1): p. 51-59.}

68. Antonisamy, P., et al., Experimental study on gastroprotective efficacy and mechanisms of luteolin-7-O-glucoside isolated from Ophiorrhiza mungos Linn. in different experimental models. Journal of Functional Foods, 2016. 25: p. 302-313.

69. Martin Calero, M.J., V. Motilva, and C. Lastra, Quercetin and naringenin; Effects on ulcer formation and gastric secretion in rats. Phytotherapy Research, 2006. 7: p. 150-153.

70. Lee, B.I., et al., Anti-ulcerogenic effect and HPLC analysis of the caffeoylquinic acid-rich extract from Ligularia stenocephala. Biol Pharm Bull, 2010. 33(3): p. 493-497.

71. Silva, L., et al., Identification of a dicaffeoylquinic acid isomer from Arctium lappa with a potent anti-ulcer activity. Talanta, 2015. 135.

72. Xu, J., et al., Hypoglycemic and hypolipidemic effects of total saponins from Stauntonia chinensis in diabetic $\mathrm{db} / \mathrm{db}$ mice. J Cell Mo Med, 2018. 22(12): p. 6026-6038.

73. Singh, S., et al., Anti-diabetic potential of triterpenoid saponin isolated from Primula denticulate. Pharm Biol, 2014. 52(6): p. 750-755.

74. Luyen, N.T., et al., Hypoglycemic property of triterpenoid saponin PFS isolated from Polyscias fruticosa leaves. An Acad Bras Cienc 2018. 90(3): p. 2881-2886

75. Yoshikawa, M., et al., Bioactive saponins and glycosides. XXIII Triterpene saponins with gastroprotective effect from the seeds of Camellia sinensis--theasaponins E3, E4, E5, E6, and E7. Chemical \&amp; pharmaceutical bulletin, 2005. 53(12): p. 1559-1564.

76. Ma, L. and J. Liu, The protective activity of Conyza blinii saponin against acute gastric ulcer induced by ethanol. J Ethnopharmacol, 2014. 158 Pt A: p. 358-363.

\section{GRAPHICAL ABSTRACT}

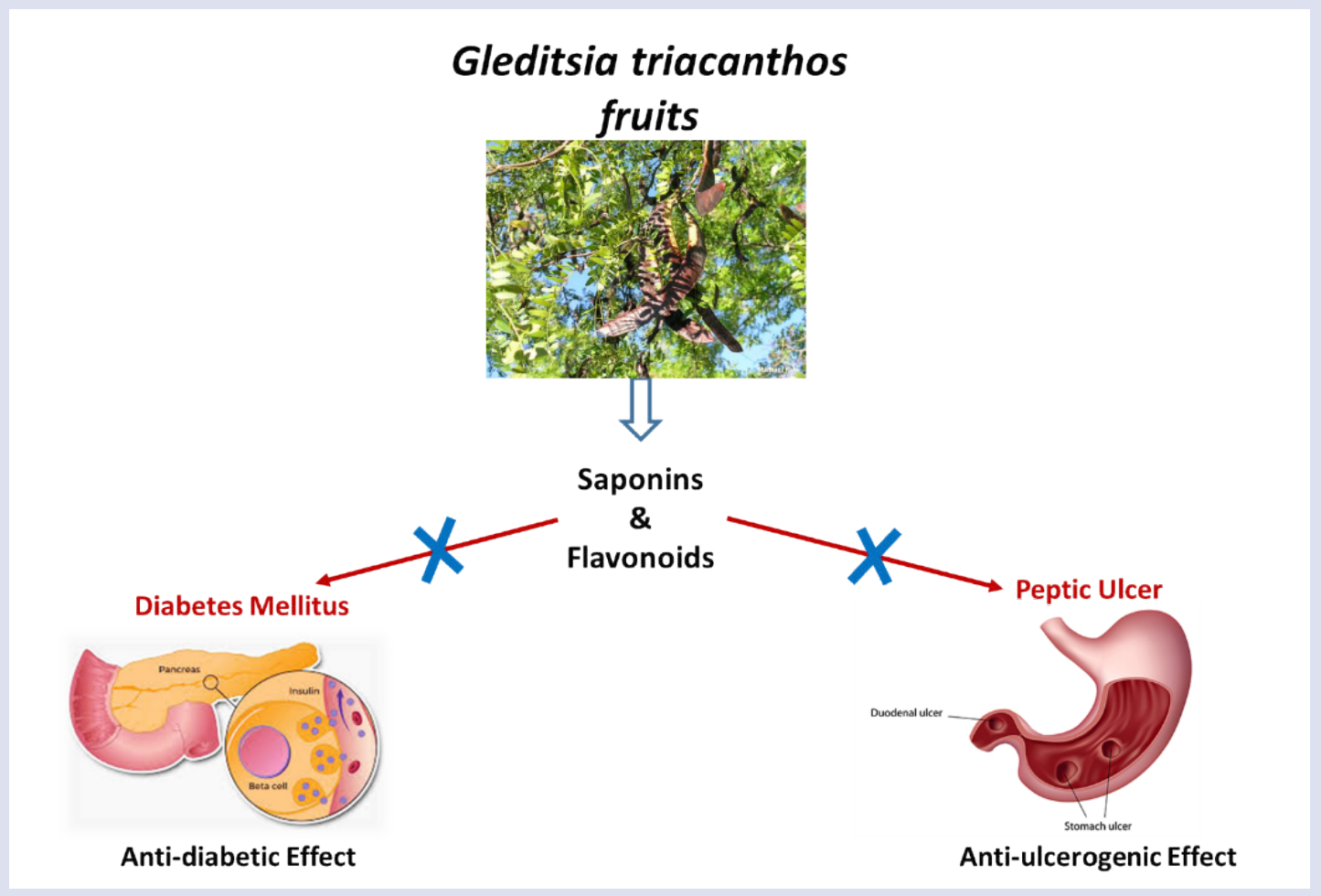

Eleven compounds were identified from Gleditsia triacanthos fruits where the methanolic fruit extract and its n-butanol fraction exhibited anti-diabetic and anti-ulcerogenic activities in rats.

\section{ABOUT AUTHORS}

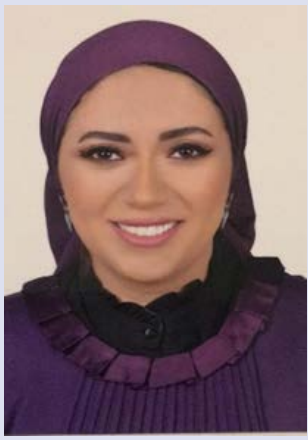

Dr. Iman Kassem works as a researcher at National Research Centre (Chemistry of Natural Compounds Department, Pharmaceutical and Drug Industries Research Division), Egypt. She received her BSc from Faculty of Pharmacy, Ain Shams University. She also received her M.Sc. and Ph.D. from Faculty of Pharmacy, Cairo University. Dr Kassem's research interest encompasses isolation and characterization of bioactive natural products. 

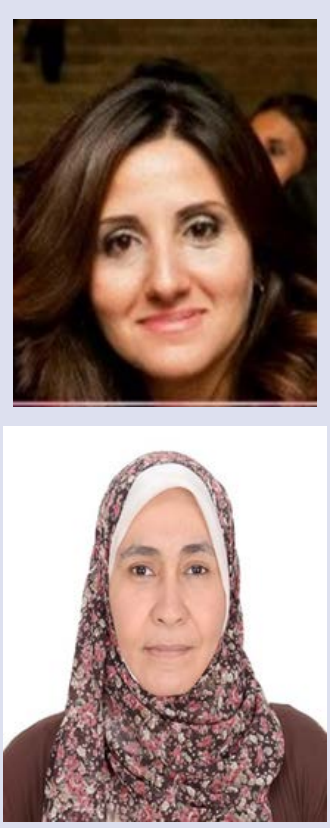

Dr. Dalia Saleh obtained her BSc, MSc and PhD from the Faculty of Pharmacy, Cairo University in 2002, 2009, and 2012, respectively. She is currently an Assistant Professor in the Pharmacology Department, Medical Division, National Research Centre. Dr. Saleh's research interests include molecular pharmacology and biochemistry, cardiovascular diseases, in-vitro pharmacology, and hepatic diseases.

Dr. Sally El Awdan is currently an Assistant Professor in the Pharmacology Department, Medical Division, National Research Centre. Dr. El Awdan published over 60 scientific articles, won 2 National Prizes and is the principle investigator in 2 research projects in addition to her Teaching experience in Heliopolis University.

Cite this article: Kassem IAA, El Awdan SA, Saleh DO. Characterization of Flavonoids and Saponins from Gleditsia triacanthos by LC-ESI/MS/MS Analysis: Pharmacological Assessment of the Anti-hyperglycemic and Anti-ulcerogenic Activities of G. triacanthos methanolic Fruit Extract and its n-Butanol Fraction. Pharmacog J. 2021;13(3): 631-9. 